\author{
ACTA MYCOLOGICA \\ Vol. 47 (2): 161-167 \\ 2012
}

\title{
The role of pH in Tuber aestivum syn. uncinatum mycorrhiza development within commercial orchards
}

\author{
PAUL WILLIAM THOMAS
}

\author{
Mycorrhizal Systems Ltd, Unit 4A, Popples Close Farm \\ HX7 7PG. UK, Paul@PlantationSystems.com
}

Thomas P.W.: The role of $\mathrm{pH}$ in Tuber aestivum syn. uncinatum mycorrhiza development within commercial orchards. Acta Mycol. 47 (2): 161-167, 2012.

The accepted advice when establishing a plantation of Tuber aestivum syn. uncinatum is that young inoculated trees should be planted on calcareous soils with a naturally high $\mathrm{pH}$ level. When a site is employed that has a naturally low $\mathrm{pH}$ level, lime is often applied to raise the $\mathrm{pH}$ to a considered ideal level of c.7.5. However, this may not be the correct approach. Here we present data from 33 data points taken from commercial truffle orchards in England, UK. Soil $\mathrm{pH}$ is correlated to Tuber aestivum syn. uncinatum mycorrhiza survivorship and development. The optimal observed $\mathrm{pH}$ was 7.51 but the actual optimal $\mathrm{pH}$ for cultivation may be higher. Sub optimal $\mathrm{pH}$ levels lead to a reduction of Tuber aestivum syn. uncinatum mycorrhiza. This reduction is not permanent and mycorrhization levels may be improved within a 12 month period by amending the soil $\mathrm{pH}$. The importance of understanding the interaction of $\mathrm{pH}$ with other variables and the results in relation truffle cultivation are discussed.

Key words: truffle, $\mathrm{pH}$, soil, mycorrhiza, Tuber aestivum

\section{INTRODUCTION}

Mycorrhizal fungi are those that form a symbiotic association with the roots of a vascular plant host and such species incorporate some of the most widely revered and economically important of all edible fungi species. The consumer demand for many of these edible species leads to high prices paid for fruiting bodies and of all the mycorrhizal species, the genus Tuber hold the most prestige and highest value per $\mathrm{kg}$. Consequently, there have been many attempts to cultivate Tuber spp. and some of these have been successful. Cultivation involves producing tree saplings with the target Tuber spp. growing on the root system and planting these trees into carefully prepared soils. This approach can be very successful and today it is estimated that over $90 \%$ of all the fresh Tuber melanosporum produced in France originates from 
inoculated trees that have been cultivated (Gerard Chevalier, personal communication September 27, 2012).

Despite the achievements in truffle cultivation, there remain many obstacles and uncertainties. There are aspects of cultivation that are debated and perceived advances in cultivation methods are often kept within closed groups, due to economic interests and an unwillingness to spread knowledge to rival cultivators. Despite variation in cultivation methods, there are several widely accepted underpinning principals in truffle cultivation based on data taken from wild-production regions. Soil $\mathrm{pH}$ is a measure of the activity of hydrogen ions, recorded as an inverse log and is often measured in a soil and water solution. Although $\mathrm{pH}$ is treated as of stand-alone importance in truffle cultivation, it is strongly related to the availability of wide range of nutrients such as $\mathrm{P}, \mathrm{K}, \mathrm{Ca}, \mathrm{Mg}, \mathrm{Zn}, \mathrm{Mn}, \mathrm{Cu}$, and $\mathrm{Fe}$.

For truffle cultivation, there are different assumed ideal $\mathrm{pH}$ levels, specific to each truffle species. For Tuber aestivum syn. uncinatum, the $\mathrm{pH}$ range within the wild is reported to be primarily 6.8-8.0 (Chevalier, Frochot 1997; Wedén et al. 2004) although within pot/glasshouse cultivation a $\mathrm{pH}$ of 7.1 has been reported as ideal (Pruett 2008). Due to a lack of clear evidence indicating the ideal $\mathrm{pH}$ level for cultivation, a figure based on wild-site data of c.7.5 is often targeted by truffle cultivators of the species Tuber aestivum syn. uncinatum.

Due to the perceived ideal $\mathrm{pH}$ level, T. aestivum syn. uncinatum is often grown in calcareous soil. Where the soil $\mathrm{pH}$ is below 7.5, the soil is often amended to raise the $\mathrm{pH}$ to around this level. Large quantities of material are often used, with applications of over 10 tonnes of limestone per hectare not being uncommon (www. PlantationSystems.com, $10^{\text {th }}$ of January, 2013).

Here we present data collated from a range of commercial truffle orchard sites in order to test the assumption that $\mathrm{pH} 7.5$ is ideal for T. aestivum syn. uncinatum cultivation.

\section{MATERIALS AND METHODS}

33 data points were used in this study from truffle plantations in England (UK) in the years 2010 and 2011. The sites were primarily acidic soils that had been subject to a stage of $\mathrm{pH}$ adjustment using crushed and ground calcareous rock. The study also incorporates a number of sites that had a naturally high $\mathrm{pH}$ level and were not subject to $\mathrm{pH}$ adjustment. An example host tree from one of these plantations is displayed in Figure 1.

Within the 33 data points are 8 sites that were sampled twice. These sites were all sampled once in 2010 and once in 2011. A second level of pH adjustment was used on these 8 sites immediately after the 2010 sampling.

Between the sites there were many variables including soil structure, nutritional profile, tree age, management methods and climate. For example, the annual reported rainfall varied between sites from $650 \mathrm{~mm}$ to $2,000 \mathrm{~mm}$ per annum.

Soil samples were taken from areas close to the base of trees within the plantations and from a depth of $2-10 \mathrm{~cm}$. Soil samples were then $\mathrm{pH}$ tested using a Growth 


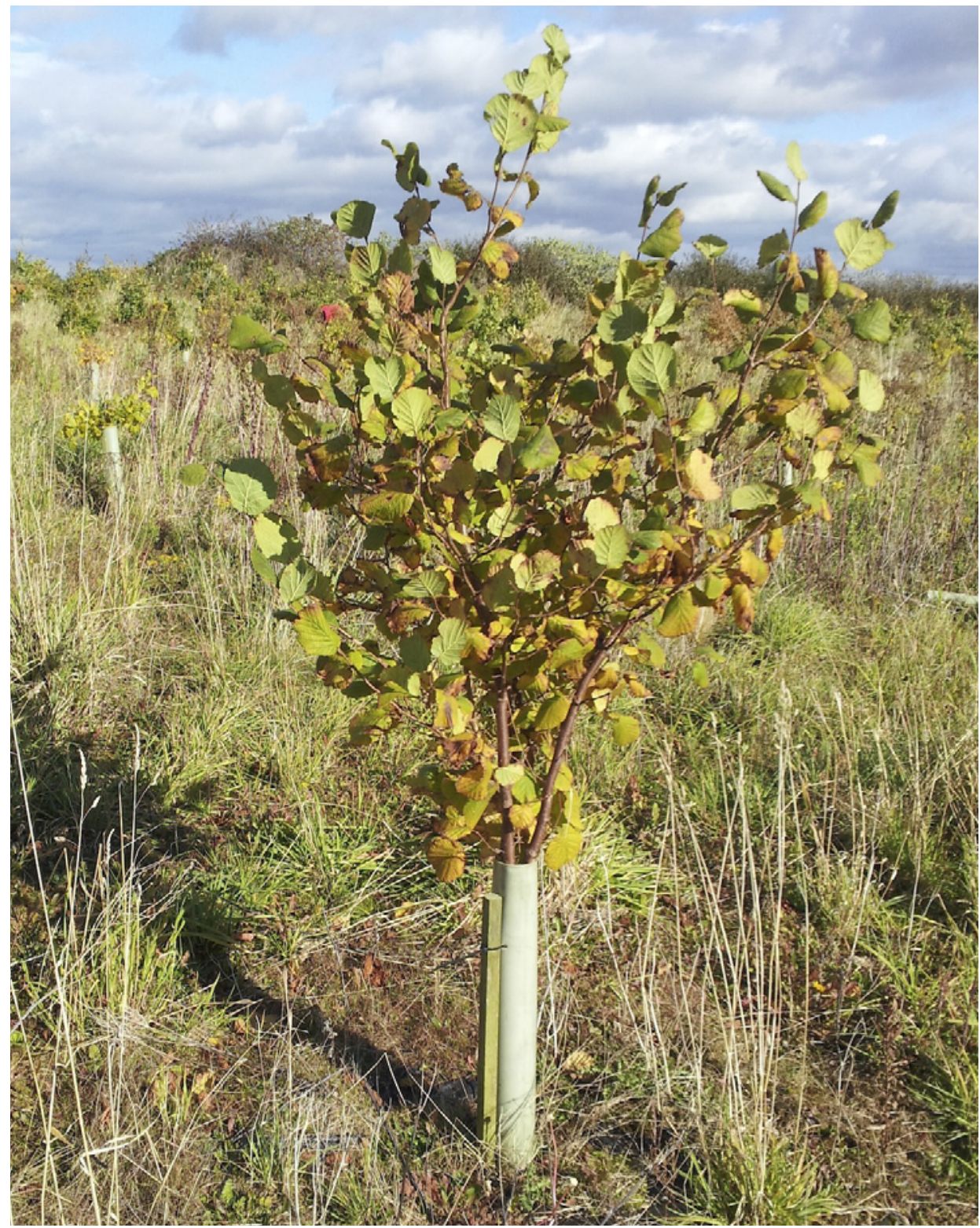

Fig. 1. An example host tree from one of the data points used in this study. Host tree species is the European hazel Corylus avellana.

Technology $\mathrm{pH}$ probe and meter calibrated with buffers $\mathrm{pH} 7.0$ and 4.0. Samples were tested as an aqueous solution in a soil to water ratio of 1:1, after agitation to combine the soil with the water.

10 trees from each sample point were randomly selected for root analysis. From each tree a root piece of $4-5 \mathrm{~cm}$ length was removed and ectomycorrhiza were identified microscopically. 


\section{RESULTS}

Root samples from 33 data points were analysed along with corresponding soil samples. Of the 33 sampling points, the sample with the lowest soil $\mathrm{pH}$ level (5.68) also had the lowest mycorrhization index of 9.27. This mycorrhization figure was $66.4 \%$ below the average for the dataset. The data point with the highest mycorrhization

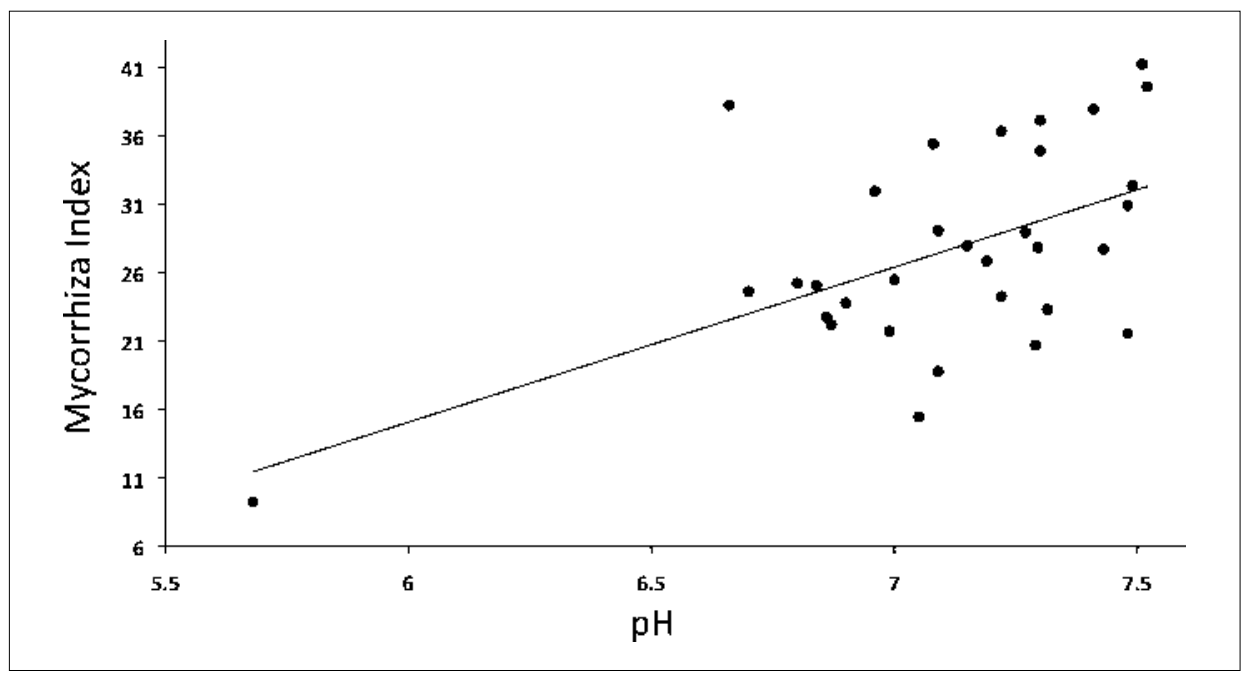

Fig. 2. Mycorrhization index of T. aestivum syn. uncinatum on host plant tree roots significantly correlated with soil $\mathrm{pH}$ level. $\left(\mathrm{R}^{2}=0.2969, \mathrm{p}<0.005\right)$.

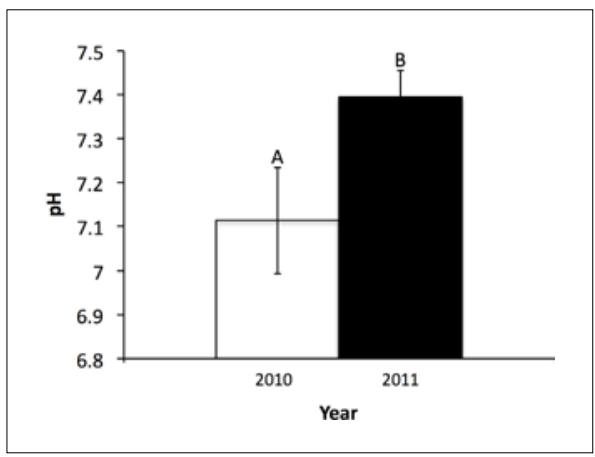

Fig. 3. Mean values $\pm \mathrm{SE}$ for the $\mathrm{pH}$ of soil from 8 sites subject to soil amendment in 2010. 2010 figures are prior to soil amendment and 2011 figures are post soil amendment. Error bars are one standard error. Values followed by different letter codes are significantly different $(T$-test, $P<0.05)$.

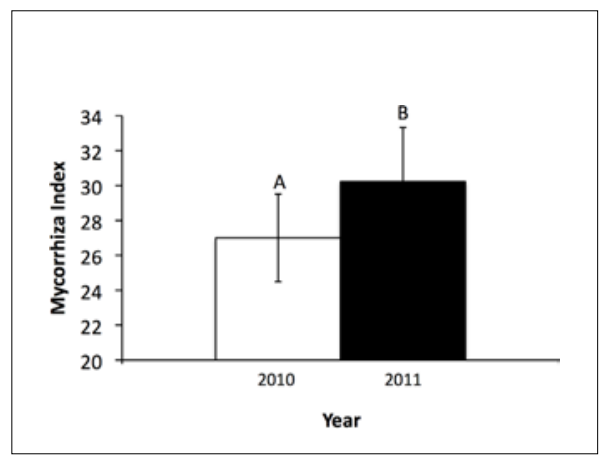

Fig. 4. Mean values $\pm \mathrm{SE}$ for mycorrhization index of T. aestivum syn. uncinatum on host plant tree roots from 8 sites subject to soil amendment in 2010. 2010 figures are prior to soil amendment and 2011 figures are post soil amendment. Error bars are one standard error. Values followed by different letter codes are significantly different ( $T$-test, $P<0.05$ ). 
index of 41.26 had the second highest measured soil pH level of 7.51. The highest mycorrhization level of 41.26 was $49.4 \%$ above the average for the dataset.

There was a significant correlation between soil $\mathrm{pH}$ and the mycorrhization index of a host plant. The results displayed in Figure 2 clearly show that the mycorrhization level increases with increasing soil $\mathrm{pH}$, up to the second highest tested $\mathrm{pH}$ level in this study of 7.51. This relationship was highly significant with $29.7 \%$ of mycorrhizal variation between sites being attributed to soil $\mathrm{pH}$ levels $\left(\mathrm{R}^{2}=0.2969, \mathrm{p}<0.005\right)$.

Of the data points displayed in Figure 2, 16 represent 8 sites that underwent additional liming and therefore, $\mathrm{pH}$ adjustment over the course of 12 months. The average $\mathrm{pH}$ of these 8 sites increased significantly from 7.1 in 2010 to 7.4 in 2011 (paired t-test, $\mathrm{p}<0.05$ ). This significant increase in $\mathrm{pH}$, displayed in Figure 3, was in parallel with a significant increase in mycorrhization levels, displayed in figure 4 (paired t-test, $\mathrm{p}<0.05$ ). The average mycohrrization levels of the 8 sites was 27.0 in 2010 and rose to 30.2 in 2011.

\section{DISCUSSION}

Our observations that Mycorrhization levels within commercial orchards are higher at higher $\mathrm{pH}$ levels, up to an observed $\mathrm{pH}$ level of 7.52 is consistent with the known sensitivity of fungi to $\mathrm{pH}$. With fungi in general, increases in biomass with corresponding reductions in $\mathrm{pH}$ levels have been observed in soil-based systems (Rousk et al. 2009) In culture, a range of fungi species are also consistently shown to be sensitive to $\mathrm{pH}$ levels with some isolates even displaying distinct infraspecific variation (Hung, Trappe 1983).

The optimal $\mathrm{pH}$ level we observed within this study was 7.5, well within the reported wild-site range of 6.8-8.0 (Chevalier, Frochot 1997; Wedén et al. 2004) However, as the data shows a linear relationship, it cannot be claimed that $\mathrm{pH} 7.51$ is the optimal level to maintain the highest level of mycorrhization on the host plants roots. The exact optimal $\mathrm{pH}$ level may be higher and more sampling is needed to ascertain the exact figure in soil-based systems. Pruett (2008) observed that the optimal $\mathrm{pH}$ level for root colonisation, with pot-grown host plants was 7.1. Our results display that this is not the case within commercial truffle orchards and that a higher $\mathrm{pH}$ level is beneficial.

At a pH level of 5.8 T. aestivum syn. uncinatum has been cultured, although mycelia expansion is reported as quicker on higher $\mathrm{pH}$ medium (Michaels 1982). The observed lower level of T. aestivum syn. uncinatum colonized host roots at $\mathrm{pH}$ levels below 6 within this study demonstrates a low tolerance of this species for suboptimal soil $\mathrm{pH}$ levels and conflicts with those reported in-culture. Clearly, cultured isolates have different requirements to those growing in symbiosis. This is mirrored in the published data for T. magnatum, where $\mathrm{pH}$ levels of 6.0 have been reported as ideal in culture (Mischiati, Fontana 1993) but in fruiting sites, soil pH is consistently reported to be above 7.23 (Bragato et al. 2004).

An exception to the stated importance of $\mathrm{pH}$ for species of the Tuber genus that are cultivated was reported by Garcia-Montero et al. (2006) where it was observed 
that $\mathrm{pH}$ has a very limited impact on production of Tuber melanosporum, although the study was constrained to the $\mathrm{pH}$ range 7.00 to 8.17. Our observations for T. aestivum syn. uncinatum contrast with the conclusions by Garcia-Montero et al. (2006).

Further, we observe that the impact of exposure to a sub-optimal $\mathrm{pH}$ level within commercial truffle orchards is not one characterised by an irreversible deleterious outcome but rather the relationship is more plastic. As we have shown here, a lower mycorrhization level can be increased by adjusting the $\mathrm{pH}$ level of the truffle orchard soil. Further, an increase in mycorrhization level is observed within a timeframe of 12 months. This observation is of importance to truffle cultivators as it suggests that attempts to improve the performance of a plantation can be successful.

The relationship between soil $\mathrm{pH}$ and mycorrhization is very clearly displayed in this study but it is important to note that $\mathrm{pH}$ alone only accounts for c. $30 \%$ of the mycorrhization variation between sites. It is also important to understand that $\mathrm{pH}$ does not operate in isolation and recognize that other factors that can impact on mycorrhization can be further modified by soil $\mathrm{pH}$. An example of this is the presence of the bacteria Pseudomonas fluorescens that was reported by Dominguez et al. (2012) to have a positive impact on colonization levels of Tuber melanosporum at sub-optimal $\mathrm{pH}$ levels.

There are many variables within commercial orchards, such as soil tilling and irrigation, climatic variables, flora and fauna, soil nutrition and soil structure which may be important in maintaining good Tuber spp. colonization levels. The interplay of these variables warrants in-depth study. For example, soil flora and fauna may be impacted by management methods such as tilling (Dorr de Quadros et al. 2012) as well as alterations in soil pH levels (Auclerc et al. 2012) and the presence/ absence of such impacted flora has been directly linked to Tuber spp. colonization levels (Dominguez et al. 2012). Therefore, the interplay of soil $\mathrm{pH}$ with other variables on the success of a truffle plantation is important and should be addressed by truffle cultivators. However, as a stand-alone measurement, $\mathrm{pH}$ is clearly of critical importance for truffle cultivation.

Mycorrhizal Systems Ltd has access to unified truffle research sites in 23 countries. This creates a large databank, a portion of which is displayed in this study. Clearly, more analysis is needed to deduce an optimal $\mathrm{pH}$ level for cultivation but the interplay of $\mathrm{pH}$ with other factors, such as climate, also warrants deeper investigation.

\section{CONCLUSION 104 (113)}

The observed optimal $\mathrm{pH}$ for mycorrhization of T. aestivum syn. unicinatum within commercial orchards is 7.51. Host plant mycorrhization rates, plotted against soil $\mathrm{pH}$, showed a linear relationship with $\mathrm{pH} 7.52$ being the highest level tested in this study. The exact optimal soil $\mathrm{pH}$ level for mycorrhization levels may be higher.

Sub-optimal $\mathrm{pH}$ levels lead to the loss of T. aestivum syn. unicinatum mycorrhiza. However, utilizing soil additives to increase the soil $\mathrm{pH}$ may reverse this decline. Significant increases in mycorrhization rates were observed 12 months after $\mathrm{pH}$ adjustment application, demonstrating that the potential of a truffle plantation can be successfully improved. 


\section{REFERENCES}

Auclerc A., Nahmani J., Aran D., Baldy V., Callot H., Gers C., Iorio E., Lapied E., Lassauce A., Pasquet A., Spelda J., Rossi J.P., Guérold F. 2012. Changes in soil macroinvertebrate communities following liming of acidified forested catchments in the Vosges Mountains (North-eastern France). Ecological Engineering 42: 260-269.

Bragato G., Sladonja B., Pursuric D. 2004. The soil environment for Tuber magnatum growth in Motovun forest, Istria. Natura Croatica 13 (2): 171-185.

Chevalier G., Frochot H. 1997. La Truffe de Bourgogne. Pétrarque, Levallois-Perret.

Dominguez J. A., Martin A., Anriquez A., Albanesi A. 2012. The combined effects of Pseudomonas fluorescens and Tuber melanosporum on the quality of Pinus halepensis seedlings. Mycorrhiza 22 (6): 429-436.

Dorr de Quadros P., Zhalnina K., Davis-Richardson A., Fagen J. R., Drew J., Bayer C., Camargo F., Triplett E. W. 2012. The Effect of Tillage System and Crop Rotation on Soil Microbial Diversity and Composition in a Subtropical Acrisol. Diversity 4 (4): 375-395.

Garcia-Montero L.G., Casermeiro M.A., Hernando J., Hernando I. 2006. Soil factors that influence the fruiting of Tuber melanosporum (black truffle). Australian Journal of Soil Research 44: 731-738. doi: 10.1071/SR060446.

Hung L.L., Trappe J.M. 1983. Growth Variation between and within Species of Ectomycorrhizal Fungi in Response to pH in Vitro. Mycologia 75 (2): 234-241.

Michaels T.J. 1982. In vitro culture and growth modeling of Tuber spp. and inoculation of hardwoods with T. melanosporum ascospores. Doctoral dissertation, Oregon State University.

Mischiati P., Fontana A. 1993. In vitro culture of Tuber magnatum mycelium isolated from mycorrhizas. Mycological Research 97 (1): 40-44.

Pruett G.E. 2008. The biology and ecology of Tuber aestivum mycorrhizae establishment in the greenhouse and the field. Doctoral dissertation, University of Missouri-Columbia.

Rousk J., Brookes P. C., Bååth E. 2009. Contrasting Soil pH Effects on Fungal and Bacterial Growth Suggest Functional Redundancy in Carbon Mineralization. Applied and Environmental Microbiology 75 (6): $1589-1596$.

Wéden C., Chevalier G., Danell E. 2004. Tuber aestivum (syn. T. uncinatum) biotopes and their history on Gotland, Sweden. Mycological Research 108 (3): 304-310. 